NASA/CR-2006-213797

\title{
Effects of Transducer Installation on Unsteady Pressure Measurements on Oscillating Blades
}

Jan Lepicovsky

QSS Group, Inc., Cleveland, Ohio 
Since its founding, NASA has been dedicated to the advancement of aeronautics and space science. The NASA Scientific and Technical Information (STI) Program Office plays a key part in helping NASA maintain this important role.

The NASA STI Program Office is operated by Langley Research Center, the Lead Center for NASA's scientific and technical information. The NASA STI Program Office provides access to the NASA STI Database, the largest collection of aeronautical and space science STI in the world. The Program Office is also NASA's institutional mechanism for disseminating the results of its research and development activities. These results are published by NASA in the NASA STI Report Series, which includes the following report types:

- $\quad$ TECHNICAL PUBLICATION. Reports of completed research or a major significant phase of research that present the results of NASA programs and include extensive data or theoretical analysis. Includes compilations of significant scientific and technical data and information deemed to be of continuing reference value. NASA's counterpart of peerreviewed formal professional papers but has less stringent limitations on manuscript length and extent of graphic presentations.

- TECHNICAL MEMORANDUM. Scientific and technical findings that are preliminary or of specialized interest, e.g., quick release reports, working papers, and bibliographies that contain minimal annotation. Does not contain extensive analysis.

- CONTRACTOR REPORT. Scientific and technical findings by NASA-sponsored contractors and grantees.
- CONFERENCE PUBLICATION. Collected papers from scientific and technical conferences, symposia, seminars, or other meetings sponsored or cosponsored by NASA.

- SPECIAL PUBLICATION. Scientific, technical, or historical information from NASA programs, projects, and missions, often concerned with subjects having substantial public interest.

- TECHNICAL TRANSLATION. Englishlanguage translations of foreign scientific and technical material pertinent to NASA's mission.

Specialized services that complement the STI Program Office's diverse offerings include creating custom thesauri, building customized databases, organizing and publishing research results ... even providing videos.

For more information about the NASA STI Program Office, see the following:

- Access the NASA STI Program Home Page at http://www.sti.nasa.gov

- E-mail your question via the Internet to help@sti.nasa.gov

- Fax your question to the NASA Access Help Desk at 301-621-0134

- Telephone the NASA Access Help Desk at 301-621-0390

- Write to:

NASA Access Help Desk

NASA Center for AeroSpace Information 7121 Standard Drive

Hanover, MD 21076 
NASA/CR-2006-213797

\section{Effects of Transducer Installation on Unsteady Pressure Measurements on Oscillating Blades}

Jan Lepicovsky

QSS Group, Inc., Cleveland, Ohio

Prepared for the

Turbo Expo 2005

sponsored by the American Society of Mechanical Engineers

Reno, Nevada, June 6-9, 2005

Prepared under Contract NAS3-00145

National Aeronautics and

Space Administration

Glenn Research Center 


\section{Acknowledgments}

The work was sponsored by the NASA Glenn Research Center under the Smart Engine Components Project managed by R.D. Corrigan as a part of the R\&T Base Propulsion and Power Program. The author would like to thank L.P. Veres, chief of the GRC Compressor Branch, for his continuous support. Significant help from E.R. McFarland, NASA Glenn Research Center, is also gratefully acknowledged.

Available from

NASA Center for Aerospace Information 7121 Standard Drive

Hanover, MD 21076
National Technical Information Service 5285 Port Royal Road Springfield, VA 22100

Available electronically at http:/ /gltrs.grc.nasa.gov 


\title{
EFFECTS OF TRANSDUCER INSTALLATION ON UNSTEADY PRESSURE MEASUREMENTS ON OSCILLATING BLADES
}

\author{
J. Lepicovsky \\ QSS Group, Inc. \\ Cleveland, Ohio 44135
}

\begin{abstract}
Unsteady pressures were measured above the suction side of a blade that was oscillated to simulate blade stall flutter. Measurements were made at blade oscillation frequencies up to $500 \mathrm{~Hz}$. Two types of miniature pressure transducers were used: surface-mounted flat custom-made, and conventional miniature, body-mounted transducers. The signals of the surface-mounted transducers are significantly affected by blade acceleration, whereas the signals of body-mounted transducers are practically free of this distortion. A procedure was introduced to correct the signals of surface-mounted transducers to rectify the signal distortion due to blade acceleration. The signals from body-mounted transducers, and corrected signals from surface-mounted transducers represent true unsteady pressure signals on the surface of a blade subjected to forced oscillations. However, the use of bodymounted conventional transducers is preferred for the following reasons: no signal corrections are needed for blade acceleration, the conventional transducers are noticeably less expensive than custom-made flat transducers, the survival rate of body-mounted transducers is much higher, and finally installation of body-mounted transducers does not disturb the blade surface of interest.
\end{abstract}

\section{NOMENCLATURE}

Only symbols not sufficiently described in the text are presented here.

$\begin{array}{ll}a & {\left[\mathrm{~m} . \mathrm{s}^{-1}\right]} \\ a_{b} & {[\mathrm{~g}]} \\ c_{\boldsymbol{p}} & {[\mathrm{l}]} \\ d & {[\mathrm{~mm}]} \\ f_{B} & {[\mathrm{~Hz}]} \\ f_{C} & {[\mathrm{kHz}]} \\ f_{N} & {[\mathrm{kHz}]} \\ L & {[\mathrm{~mm}]}\end{array}$

$$
\begin{array}{ll}
\text { Ma } & {[1]} \\
p_{A} & {[\mathrm{kPa}]} \\
x, X & {[\mathrm{~mm}]} \\
\varphi & {[\mathrm{dg}]}
\end{array}
$$

\section{INTRODUCTION}

Blade flutter and the associated high cycle fatigue problems are very detrimental to the structural health of airfoil cascades. The origins of stall flutter are still not fully understood. Among the basic information needed for flutter prediction is the unsteady pressure loading on the oscillating blades. Yet measuring oscillating pressure on fan or compressor blades within a modern engine is nearly an impossible task. Consequently, flutter conditions are simulated in linear cascades with blades undergoing forced oscillations. However, measuring unsteady pressures on the oscillating blades is not easy even under these simplified conditions. Conventional static taps on oscillating blades average the fluctuating pressures, and thus do not furnish enough information to facilitate effective unsteady analysis of flow and blade structure interaction. The blades must be instrumented with miniature pressure transducers to acquire the needed data on flutter effects.

\section{NASA TRANSONIC FLUTTER CASCADE}

The NASA Transonic Flutter Cascade (TFC) facility has been used to investigate the behavior of a cascade of modern, low-aspect ratio fan blades operating near the stall flutter boundary that occurs at high incidence angles and high subsonic and transonic relative Mach numbers (Refs. 1 through 4). The facility combines a linear cascade wind tunnel with a high-speed drive system that imparts pitching oscillations to the cascade blades. The test cascade consists of nine blades. 
All nine blades or any single blade can be oscillated at frequencies up to $500 \mathrm{~Hz}$ with amplitudes up to $2.4 d g$. A view of the cascade test section is shown in Fig. 1.

Originally, two blades were instrumented with special flat, surfacemounted transducers flush with the blade contour (blades labeled $K S 1$ and $K S 2$ ). The blades must be grooved before the transducers can be flush mounted. This

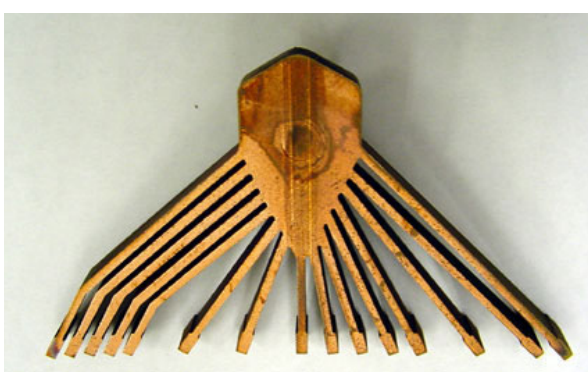

Fig. 2 EDM electrode.

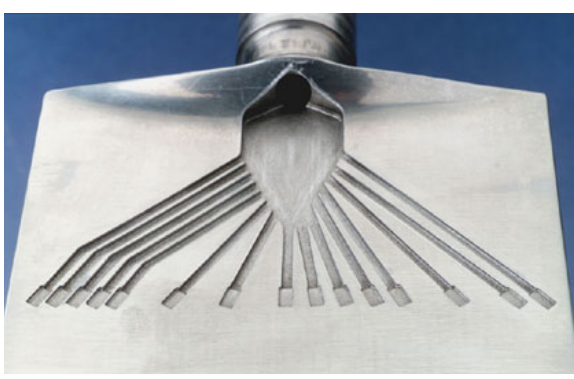

Fig. 3 Grooved blade KS2. machining was done with the Electro Discharge Machining (EDM) method. The EDM electrode and the grooved blade are shown in Figs. 2 and 3 (Ref. 5). Fully instrumented blade KS2 is shown in Fig. 4. Coordinates of transducer positions are given in Tab. 1.

The main reason for selecting flush-mounted transducers was to maximize the frequency response of this pressure measurement system. On the other hand, there are several disadvantages to this approach. Although flat transducers are very thin, they have a relatively large diameter; consequently, they average unsteady pressures over a circle of at least $2 \mathrm{~mm}$ in diameter. The sensing elements are exposed, have minimal protection, and are vulnerable to mishandling. Our experience is that the 'fatality' rate due to mishandling is very high. To protect the sensing element on the blade surface, the transducers are overlaid with a layer of silicone rubber. This layer, however, also acts as a damper and decreases the transducer frequency response. Also, the blade surface where the unsteady pressures are measured is disturbed to some extent because of all the 'digging' on this side of the blade. However, the biggest disadvantage of surface-mounted pressure transducers is that they are subject to acceleration effects which severely contaminate - and can even overwhelm the measure pressure signal. The problem of acceleration effects will be discussed later.

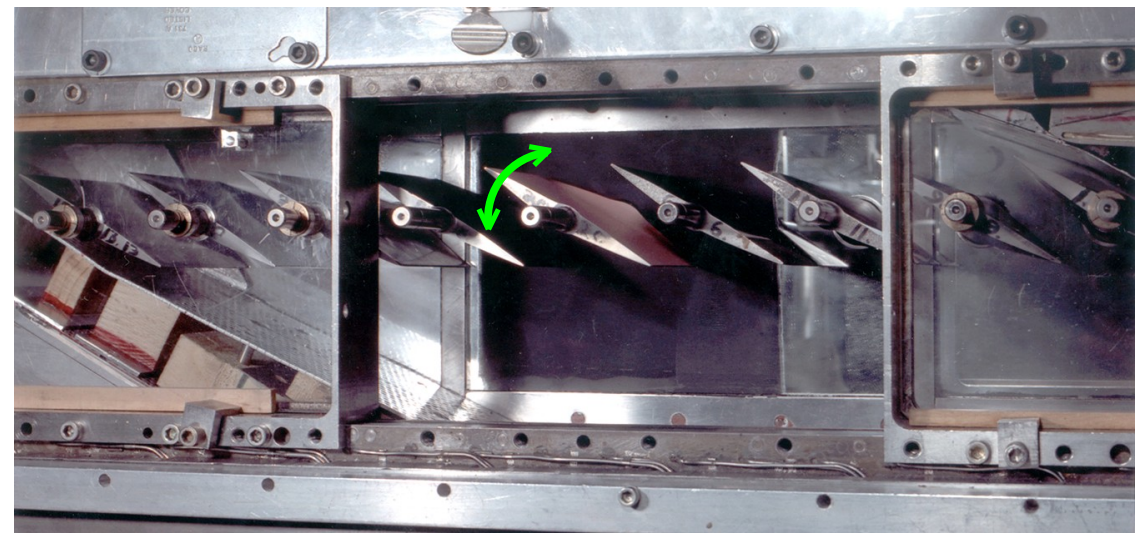

Fig. 1 Test section of the NASA Transonic Flutter Cascade.

\section{DATA ACQUISITION}

Signals from the miniature pressure transducers were amplified using DC amplifiers, and recorded in a digital form using a dedicated data acquisition system. The A/D board employed had sufficiently high resolution to give a pressure resolution of $24 \mathrm{~Pa}$ for transducers with $100 \mathrm{kPa}$ full scale range. All records were of the same length, $4.2 \mathrm{~s}$ (precisely 80000 points acquired at a scanning frequency of $19.2 \mathrm{kHz})$.

All active pressure transducers were frequently calibrated under static conditions. The instrumented blades were regularly used to measure unsteady pressures on blades that were not oscillated. Example of the measurement accuracy achieved under steady state flow conditions are shown in Fig. 5 for two cascade inlet Mach numbers of 0.5 and 0.8. Three blades ( $S 1, K S 1$, and $K S 2$ ) were instrumented during the course of this test program. Blade $S 1$ was instrumented with conventional static taps (double cyan line), and blades KSI 


\begin{tabular}{|c|c|c|c|c|c|c|c|c|c|c|c|c|c|c|c|c|c|c|c|c|c|c|}
\hline $\mathrm{X}(\mathrm{mm})$ & -46.2 & -39.3 & -36.2 & -35.2 & -33.1 & -29.9 & -28 & -26.8 & -22.6 & -17.9 & -15.4 & -9.1 & 0.1 & 4.5 & 8.8 & 13.3 & 17.7 & 26.6 & 30 & 35.5 & 40 & 42.6 \\
\hline & & & & & & & & & & & & & & & & & & & & & & \\
\hline Port & & $A$ & $B$ & & 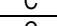 & D & & $\mathrm{E}$ & 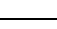 & 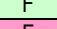 & - & G & $\mathrm{H}$ & 1 & $\mathrm{~J}$ & K & L & $\mathrm{M}$ & & $\mathrm{N}$ & 0 & \\
\hline \multirow{2}{*}{\multicolumn{23}{|c|}{ Transducer }} \\
\hline & & & & & & & & & & & & & & & & & & & & & & \\
\hline \multirow{2}{*}{\multicolumn{23}{|c|}{ Blade KS3 }} \\
\hline & & & & & & & & & & & & & & & & & & & & & & \\
\hline Port & A & B & & C & & & $\mathrm{D}, \mathrm{E}$ & & & & & & & & & & & & & & & $\mathrm{F}$ \\
\hline Transducer & & & & & & A & D & B & C & & $E$ & & & & & & & & $\mathrm{~F}$ & & & \\
\hline
\end{tabular}

Tab. 1 Coordinates of pressure ports and transducer locations on blades KS2 and KS3.

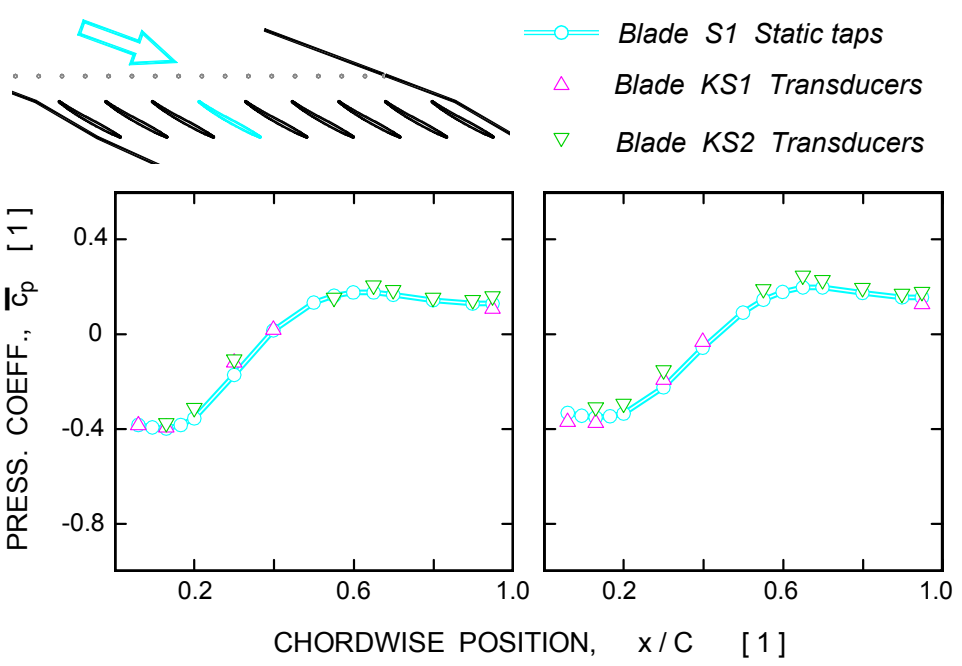

Fig. 5 Comparison of static tap and miniature transducer time average data.

(red delta symbols) and $K S 2$ (green gradient symbols) were instrumented with surface-mounted flat transducers. The plots in Fig. 5 show pressure coefficient distributions over the suction surface of a blade. The data collapse is very good. The maximum difference between the static tap and time-averaged miniature transducer data is less than $2 \%$ of the local dynamic pressure value at a Mach number of 0.5 , and about $5 \%$ at a Mach number of 0.8 (Ref. 5).

For the tests where instrumented blades were oscillated, signals from the blade transducers were recorded simultaneously with a once-per-period (OPP) signal from the driving shaft of the blade oscillation mechanism. The OPP signal was used as a base for ensemble averaging of pressure transducer signals during the post processing phase. Due to the constant number of samples in every data record, the number of periods for averaging increases with the blade oscillation frequency, whereas the number of samples in the resulting ensemble average (period resolution) is inversely proportional to the blade oscillation frequency. Specifically, for a frequency of $50 \mathrm{~Hz}$ the ensemble consists of 200 periods, while for 500 $\mathrm{Hz}$ blade frequency the ensemble consists of 2000 periods. The resolution of the nondimensional ensemble average period is 0.0025 for $50 \mathrm{~Hz}$ frequency, and 0.025 for the blade oscillation frequency of $500 \mathrm{~Hz}$.

\section{ACCELERATION EFFECTS}

As stated above, the surface-mounted flat transducers are subject to acceleration effects that severely contaminate the pressure signal. A detailed diagram of a surfacemounted transducer is shown in Fig. 6. As seen here, the transducer sensing element (a silicone diaphragm) lies in a plane that is perpendicular to the acceleration vector as the blade oscillates. The forces acting on the diaphragm are shown schematically in Fig. 7. With no pressure difference and no acceleration acting on the transducer, the diaphragm is in its neutral position, and the voltage signal generated by the transducer is constant. If a positive pressure difference is applied to a transducer, the diaphragm deflects upwards, and the transducer generates increased voltage that is a measure of the increased pressure. If however, the transducer is subjected to a positive acceleration, the diaphragm deflects downwards due to its inertia, and the transducer generates lower voltage. Positive acceleration mimics a negative pressure difference. If a transducer is located in a vibrating environment, and the acceleration signal is not known, there is no way to distinguish between the transducer signal components caused by pressure and acceleration variations.

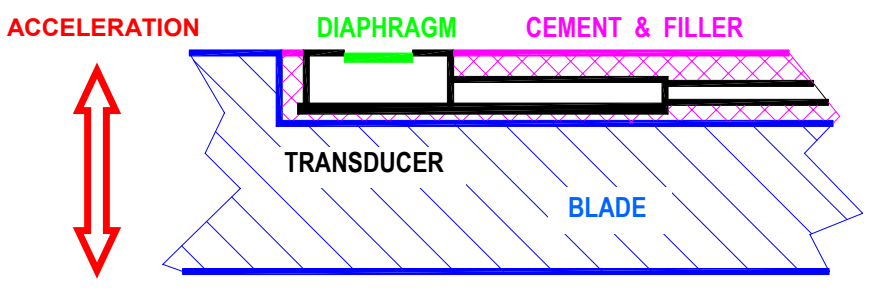

Fig. 6 Surface-mounted pressure transducer.

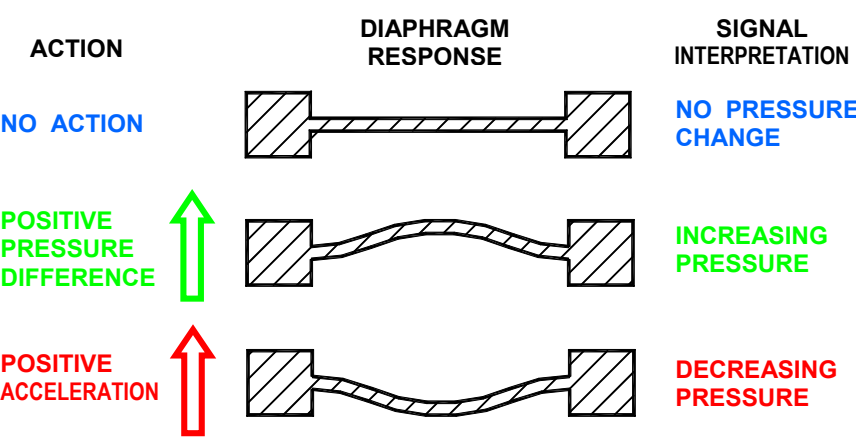

Fig. 7 Pressure difference and acceleration loading. 


\section{SURFACE-MOUNTED PRESSURE TRANSDUCERS (BLADE KS2)}

Diagrams in Fig. 8 show the response of pressure transducers to acceleration in the absence of airflow. The blade was oscillated with angular amplitude of $1.2 \mathrm{dg}$ about its stagger angle position of $30 \mathrm{dg}$. Further, the results are shown for three oscillation frequencies of $100 \mathrm{~Hz}, 300 \mathrm{~Hz}$, and 500 $H z$. The columns correspond to three pressure transducers located on blade $K S 2$ at ports $F, I$, and $O$. The left column corresponds to the transducer which is upstream (left) of the blade pitching axis. As the blade leading edge moves up from its neutral position the transducers left of the pitching axes experience negative acceleration (deceleration), while the transducers right of the pitching axis experience positive acceleration with respect to the blade surface, and also to the plane of transducer diaphragm. Therefore the transducers left of the pitching axis initially show pressure decreases while the transducers right of the pitching axis show pressure increases. The apparent pressure data were fitted with a sine wave that represents the first harmonic of the unsteady pressure data. For simplicity, the amplitude and phase of this fitted first harmonic sine wave will be used in further analysis.

The acceleration load increases both with increasing frequency of blade oscillations, and with increasing distance between the transducer position and the pitching axis. Summary plots of blade local acceleration, amplitude, and phase of the pressure signal's first harmonic are shown in Fig. 9. The amplitude of apparent pressure oscillation increases parabolically with increasing local acceleration in both directions away from the pitching axis. The phase changes $180 \mathrm{dg}$ at the zero acceleration position, which is at the pitching axis. It appears that the oscillation amplitude of apparent pressure due to acceleration effects for local blade accelerations below the level of $100 \mathrm{~g}$ is less than $1 \mathrm{kPa}$, which is almost equal to the expected error of the transducer reading for the given pressure range (100 $\mathrm{kPa}$ absolute pressure). Consequently, the acceleration effects for local blade accelerations below the level of $100 \mathrm{~g}$ can be ignored.

Once the flow in the cascade is turned on, the pressure transducer response is more complicated. The transducer diaphragm is now loaded by flow induced pressure fluctuations as well as by inertia forces, which result in a complex signal pattern. The series of diagrams in Fig. 10 depicts the response of pressure transducers along the blade $K S 2$ while oscillating at $300 \mathrm{~Hz}$ at a cascade inlet Mach number of 0.5 . A similar set of data, however at a cascade inlet Mach number of 0.8 is shown in Fig. 11. Summary plots for both flow conditions and all oscillation frequencies tested are presented in Figs. 12 and 13. The most noticeable change in the plots of oscillation amplitude is that the flow exhibit strong induced oscillations at the midchord location, which is at the pitching axis where blade local acceleration is zero. The highest oscillation amplitude is for the transducer at the port $F$ (upstream of the pitching axis), and this amplitude increases with increasing inlet Mach number as well as with increasing frequency of blade oscillations, particularly for the higher inlet Mach number (Fig. 13). As seen in Fig. 9, for the flow-off case the oscillation amplitude increases with increasing acceleration. For the cascade flow on (Figs. 12 and 13), however, the oscillation amplitude downstream of the pitching axis initially decreases with the increasing acceleration, and then starts to increase. This change in trend occurs for local acceleration of

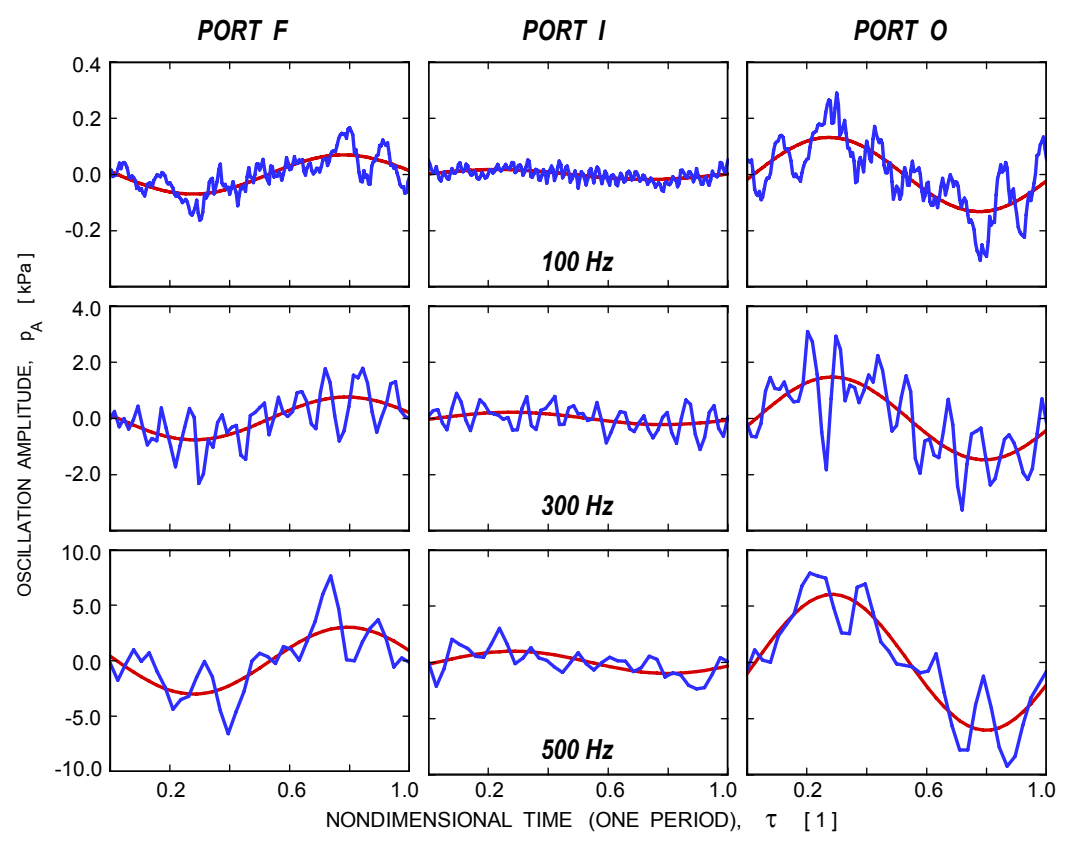

changes $180 \mathrm{dg}$ at the zero acceleration position, which is at the

\footnotetext{
Fig. 8 Apparent unsteady pressure due to acceleration effects on
Surface-mounted transducers (blade $K S$ 2).

Fig. 8 Apparent unsteady pressure due to acceleration effects on
Surface-mounted transducers (blade $K S 2$ ).
}

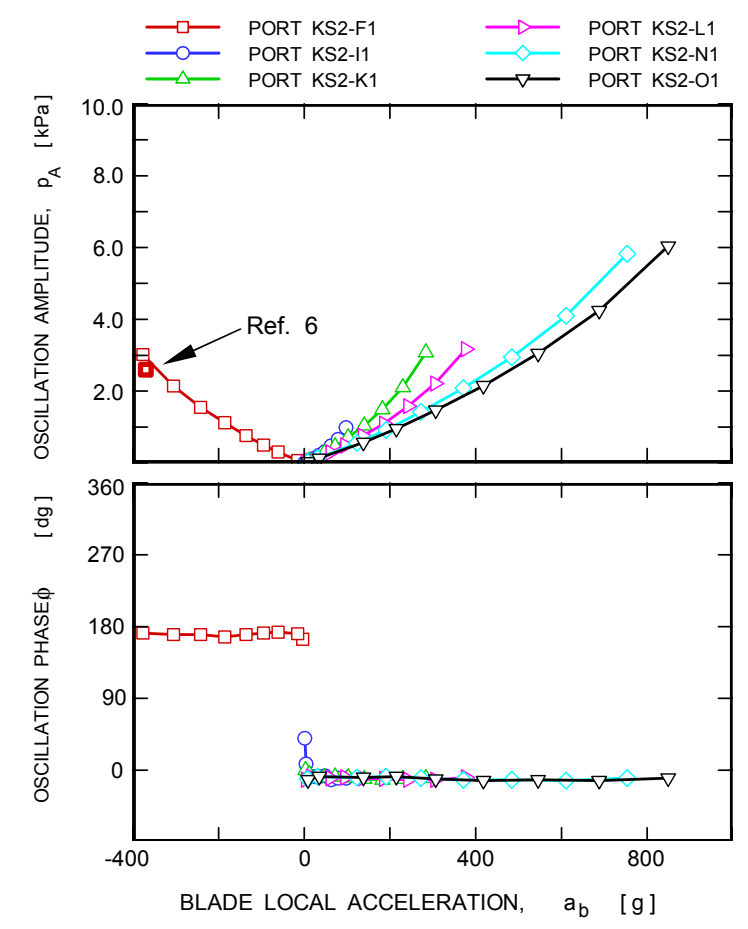

Fig. 9 Acceleration effects on surface-mounted transducers for no cascade flow. 

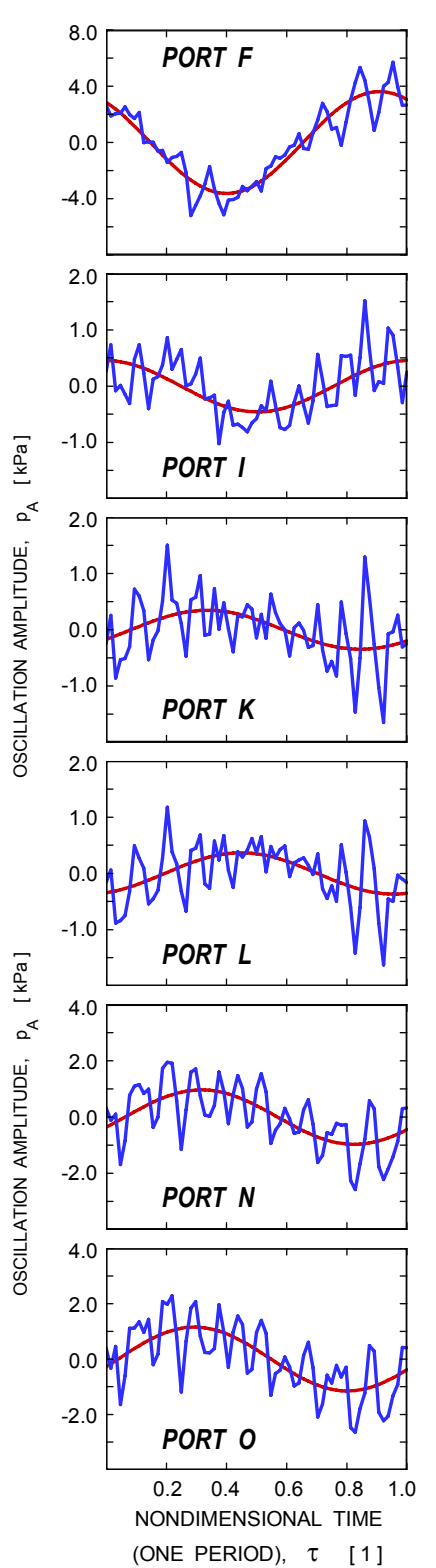

Fig. 10

Pressure signals for inlet flow at Mach number 0.5 and blade oscillations of $300 \mathrm{~Hz}$.

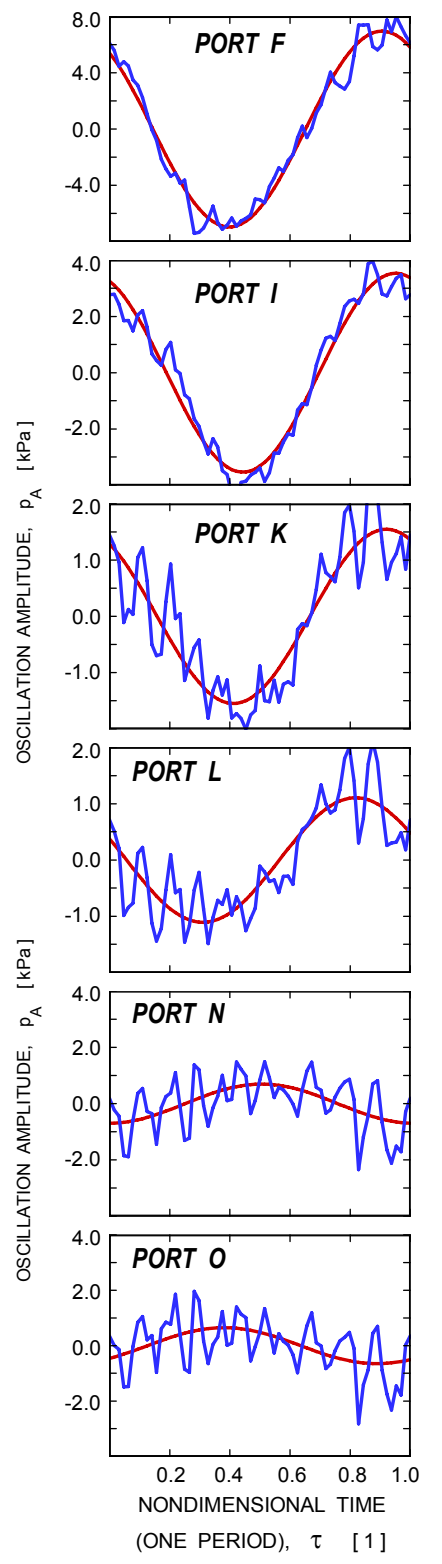

Fig. 11

Pressure signals for inlet flow at Mach number 0.8 and blade oscillations of $300 \mathrm{~Hz}$.

about $40 \mathrm{~g}$ to $50 \mathrm{~g}$ for inlet Mach number of 0.5 (Fig. 12), and for acceleration of $100 \mathrm{~g}$ for inlet Mach number of 0.8 (Fig. 13). The phase of the detected oscillation signal exhibits more complex behavior in the flow-on condition than in the flow-off condition. This behavior occurs because the pressure fluctuations are convected with the flow over the blade surface, which varies the phase angle with respect to the transducer location. For an inlet Mach number of 0.5 , a sudden change in the oscillation phase can still be detected at the blade pitching axis, but for the higher Mach number this change becomes less pronounced. Obviously, both the amplitude and phase of the transducer pressure signals are strongly influenced by the acceleration effects.

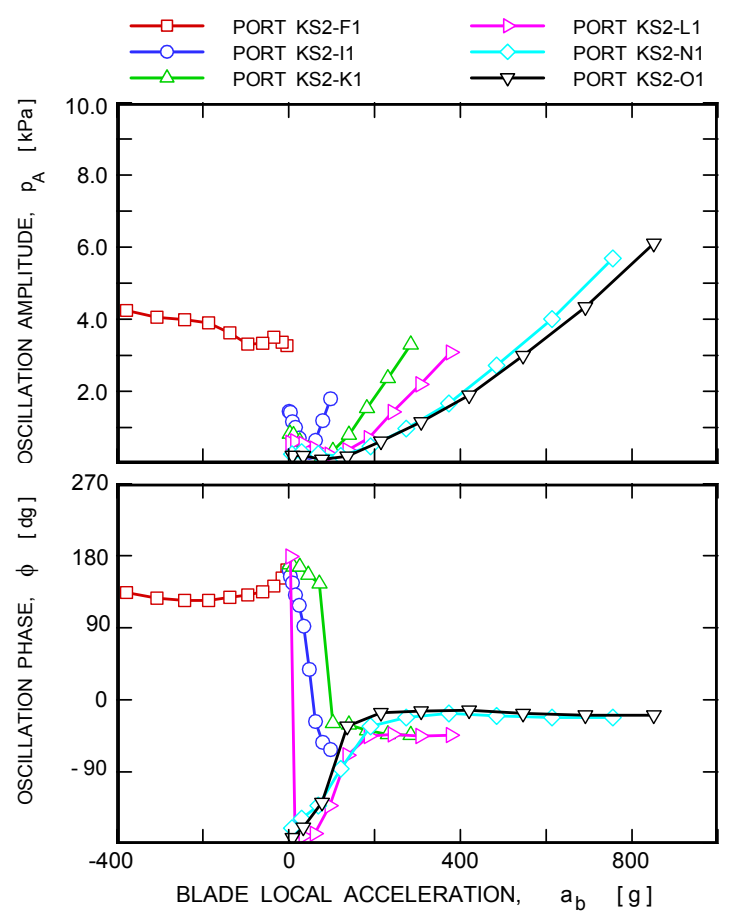

Fig. 12 Acceleration effects on surface-mounted transducers for Mach number of 0.5 .

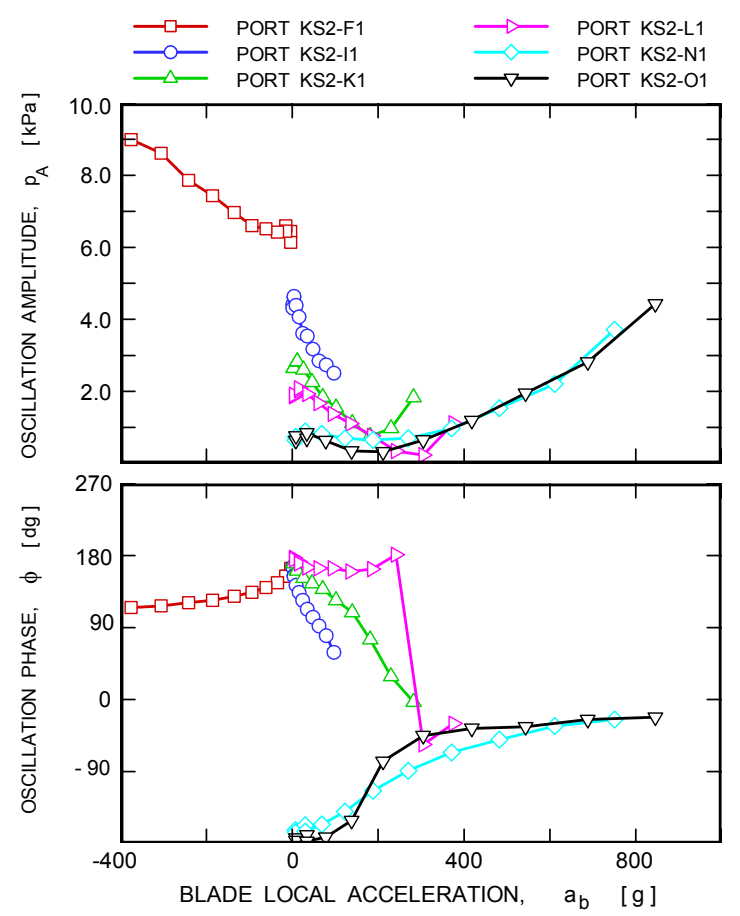

Fig. 13 Acceleration effects on surface-mounted transducers for Mach number of 0.8 .

\section{CORRECTION FOR ACCELERATION EFFECTS}

The problem of data contamination due to acceleration effects was addressed in previous work in this facility (Ref. 6). It appears, based on the short description given in Ref. 6, that the correction for acceleration effects was based on the measured amplitude of the apparent pressure fluctuations only, 


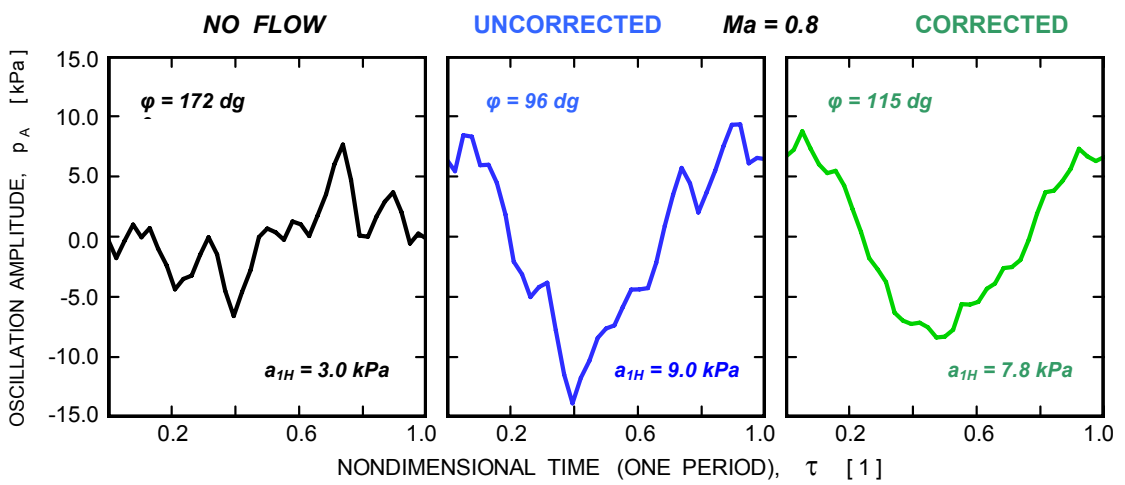

Fig. 14 Uncorrected and corrected pressure signals for blade oscillation frequency of $500 \mathrm{~Hz}$ and local acceleration of $375 \mathrm{~g}$. phase of the apparent pressure fluctuations. The proposed signal correction is based on an assumption of superposition of true pressure fluctuations and acceleration effects (Ref. 7). For each test conditions two sets of data were recorded: one with flow-off in the cascade, the other with flow at a selected cascade inlet Mach number. Both records were of the same length of $4.2 \mathrm{~s}$. The frequency of blade oscillations was maintained for both conditions with accuracy better than $1 \%$ of the frequency value. The OPP signal was used to build ensemble averages of flow-off and flow-on pressure signals. Based on the assumption of linear superposition, the acceleration effects can be removed by simply subtracting the ensemble average for the flow-off and the phase of the pressure signal was not corrected. The blades were oscillated at no flow conditions in a low pressure chamber $(1.2 \mathrm{kPa})$ outside of the TFC facility, and the measured 'pressure' signal was fully attributed to the acceleration effects. It is stated in Ref. 6 that "at $370 \mathrm{~Hz}$, the correction for the upper surface leading edge transducer was $2.6 \mathrm{kPa}$ ". This data point is plotted in Fig. 9. As seen here, this data point is perfectly in line with data acquired for no flow conditions in the TFC facility at ambient pressure.

In order to retrieve the amplitude and phase behavior of the true flow pressure fluctuations, the acquired signal from the surface-mounted pressure transducers must be corrected to remove the acceleration effects for both, the amplitude of apparent pressure fluctuations as well as for phase of the

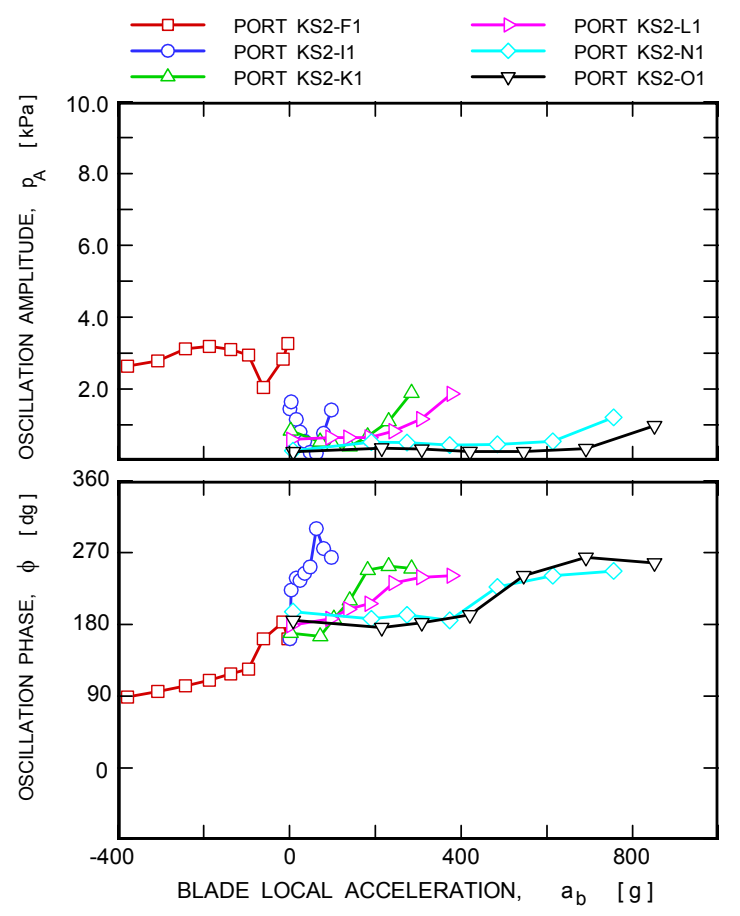

Fig. 15 Pressure signals from surface-mounted transducers corrected for acceleration effects for inlet Mach number of 0.5 . condition from the signal ensemble average generated for the flow-on condition.

The result of this correction is shown in Fig. 14 for the transducer at port $F$ at an inlet Mach number of 0.8 , and blade oscillating frequency of $500 \mathrm{~Hz}$. Summary plots of corrected pressure fluctuations for the cascade inlet Mach numbers of 0.5 and 0.8 are presented in Figs. 15 and 16 . These plots are qualitatively different from plots of uncorrected data shown in Figs. 12 and 13. First, the amplitude plots show high level of pressure fluctuations upstream of the pitching axis and a significant drop in the amplitude of pressure fluctuations downstream of the pitching axis. This effect is particularly obvious at the cascade inlet Mach number of 0.8 (Fig. 16). The

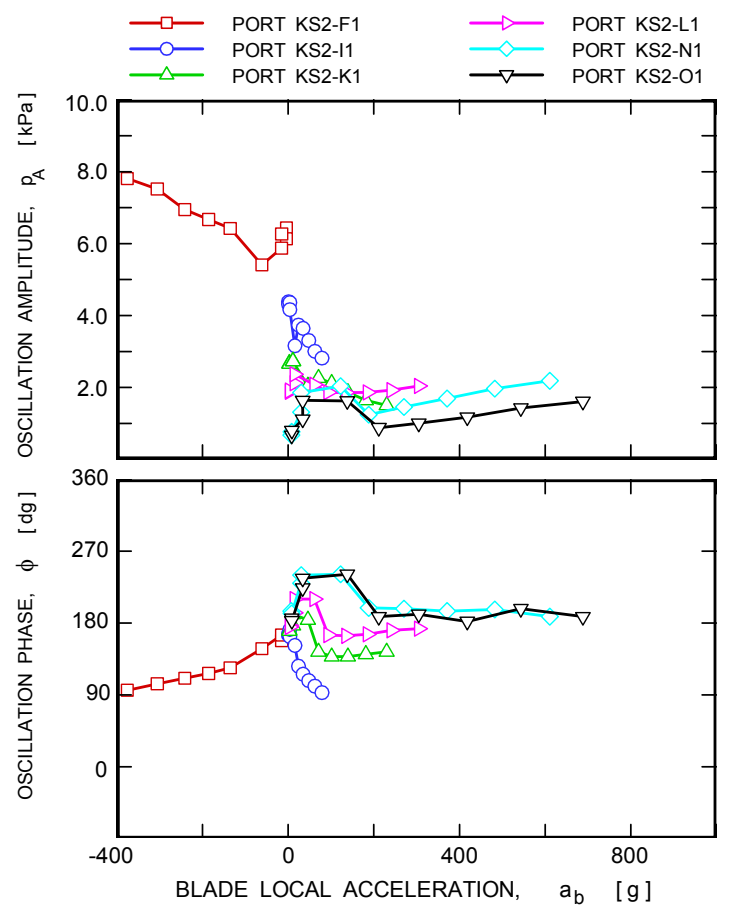

Fig. 16 Pressure signals from surface-mounted transducers corrected for acceleration effects for inlet Mach number of 0.8 . phase plots show significantly smaller phase change at the 
pitching axis than was the case for the uncorrected data. In summary, the corrected data indicate strong induced pressure fluctuations over the upstream half of the oscillating blade with a rapid decrease of the oscillation amplitude as the flow passing by the blade pitching axis. The pressure oscillations over the downstream half of the blade are very weak with amplitude that is of the same order as the expected transducer error band. The phase of the pressure fluctuations does not exhibit a sudden change at the pitching axis as it does for the flow-off condition.

\section{BODY-MOUNTED PRESSURE TRANSDUCERS (BLADE KS3)}

Due to the high 'fatality' rate of handling the fragile surface-mounted pressure transducers, not enough active transducers were available to acquire the desired data. Instrumenting a new blade replacing all transducers would be very costly, and a decision was made to install transducers on a new blade only in the locations of malfunctioned ones. Further, it was decided to replace flat surface-mounted custom-installed transducers with less expensive standard, miniature pressure transducers. Due to the blade size restrictions, the conventional miniature pressure transducer must be installed body-mounted as indicated in Fig. 17. In this approach, the pressure transducer is mounted just below the blade surface. All the 'digging' in the blade is done from the opposite side of the blade, thus leaving the surface of interest untouched. A photograph of the blade during EDM on the pressure side is shown in Fig. 18. The transducer is connected to the surface by a $2-\mathrm{mm}$ long tube $0.5 \mathrm{~mm}$ in diameter. Such a short connecting tube does not practically affect the transducer frequency response. The frequency response of body-mounted transducers will be discussed later, and it will show that for the frequency range up to $500 \mathrm{~Hz}$ used in the NASA TFC facility the connecting tube can be up to $15 \mathrm{~mm}$ in length before any noticeable change on the overall frequency response is noted. Five out of six transducers on blade KS3 were equipped with connecting tubes as can be seen on the drawing in Fig. 19. The reason for this layout is that the measuring ports could be placed much closer to the leading and trailing edges - a place where the blade is too thin to accommodate a transducer. To keep the same frequency response for all the transducers, the connecting tubes were used even in place where the blade had sufficient thickness. Only one transducer was equipped with a

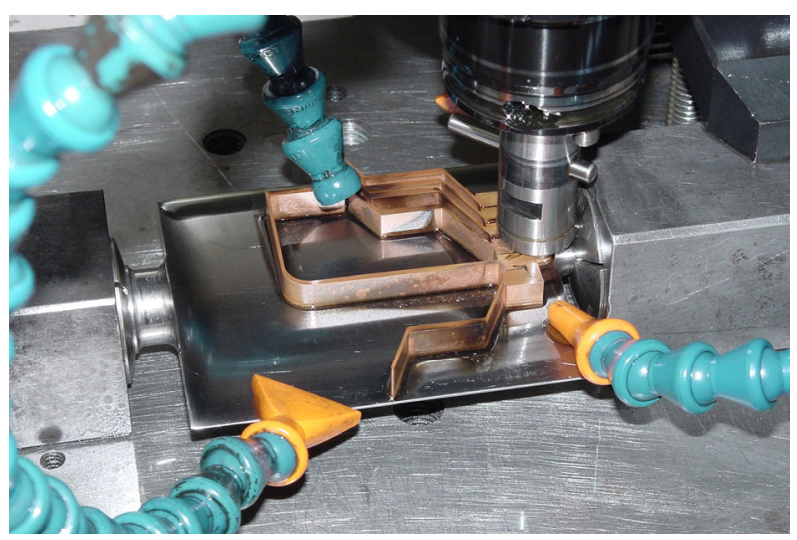

Fig. 18 Blade KS3 in the EDM machine.

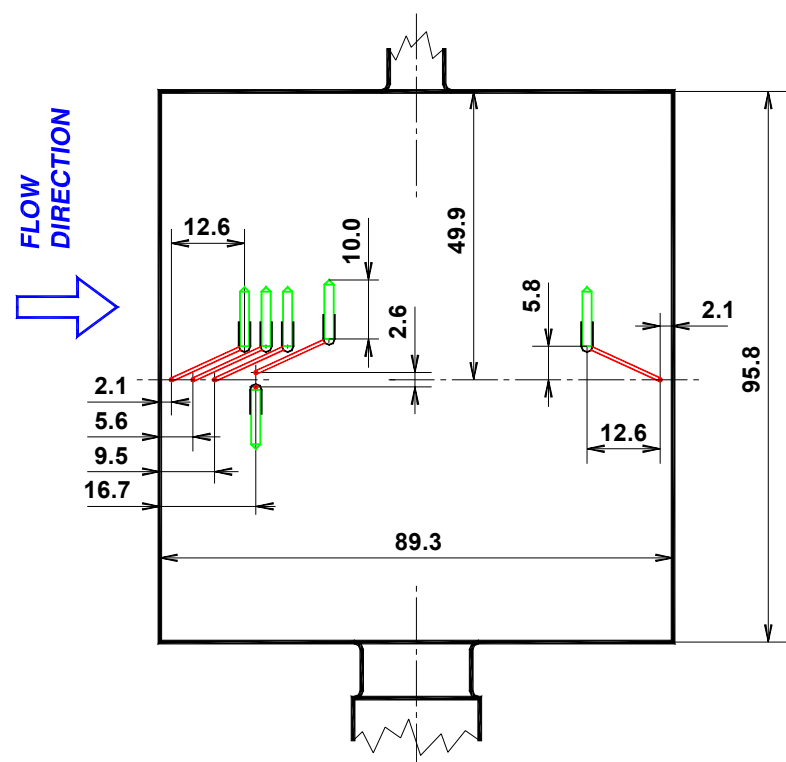

Fig. 19 Layout of body-mounted miniature pressure transducers on suction side of blade KS3.

short tube of $2 \mathrm{~mm}$ in length (port $D$ ) to assess the effects of the connecting tube on the overall frequency response. Bodymounted transducers are better protected against damage due to mishandling than the transducers mounted on the blade surface.

The major benefit of the body-mounted transducers is that the transducer diaphragm is oriented perpendicular to the blade surface; this orientation minimizes the transducer's sensitivity to acceleration effects, and eliminates the need to correct the signal for acceleration effects. The result is a significant improvement in the accuracy of pressure measurement on oscillating blades. The graphs in Fig. 20 show the significantly reduced effect of blade acceleration on signals for selected ports and frequencies. A summary plot of the signal first harmonic for all flow-off tests is shown in Fig. 21. As seen here, the

Fig. 17 Body-mounted pressure transducer. 


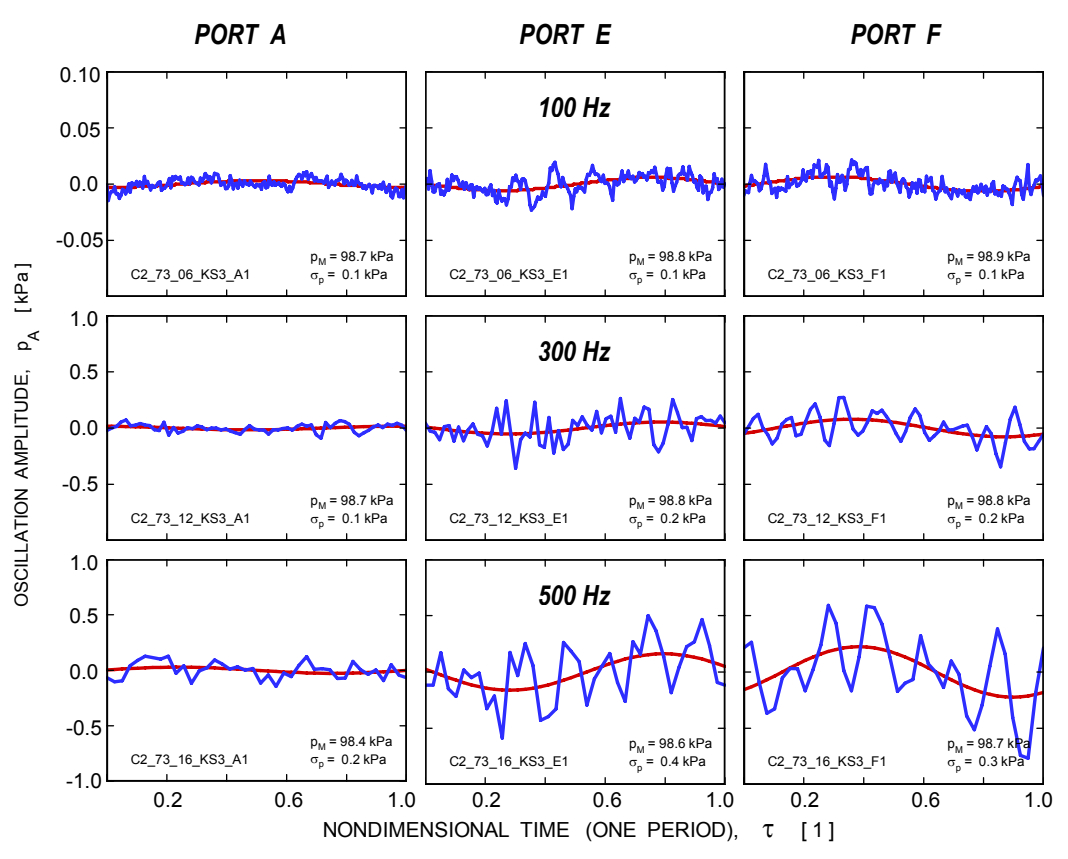

Fig. 20 Apparent unsteady pressure due to acceleration effects on body-mounted pressure transducers (blade $K S 3$ ).

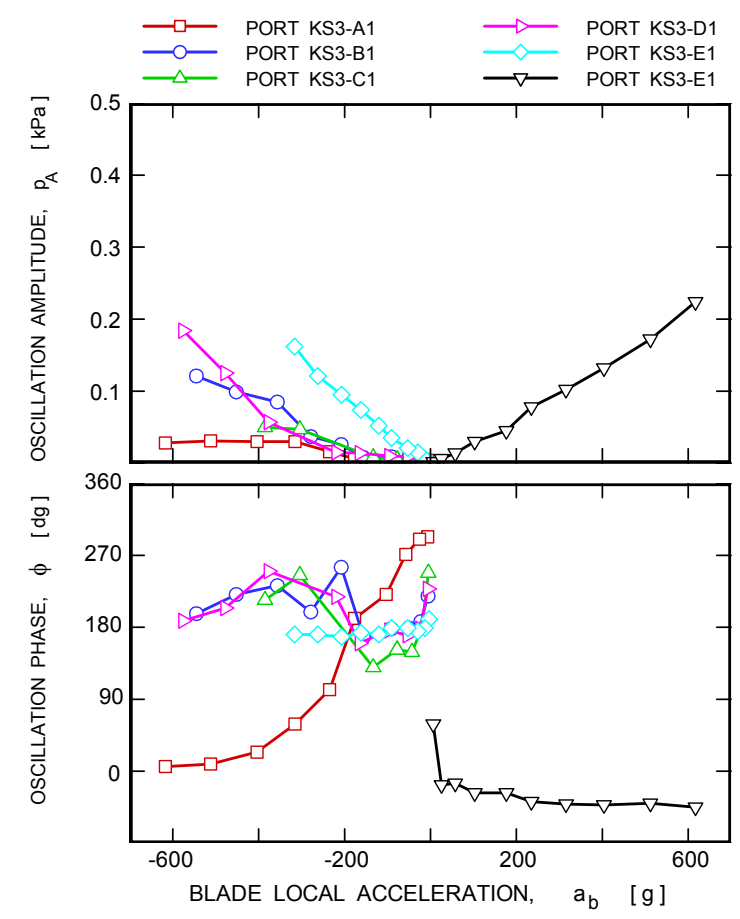

Fig. 21 Acceleration effects on body-mounted transducers for no cascade flow.

maximum amplitude of the apparent pressure fluctuation for flow-off conditions is less than $0.3 \mathrm{kPa}$, which is more than twenty times less than surface-mounted transducers (see Fig. 9). The acceleration effects are nearly negligible, and the signal does not require any acceleration related corrections.
The phase diagram is shown here only for completeness. For most of the ports, with the exception of port $A$, the phase follows the blade motion. The signal for port $A$ is very flat, as seen in the left column of Fig. 20, which does not allow determination of the signal phase with sufficient accuracy.

Summary plots for inlet Mach numbers of 0.5 and 0.8 are shown in Figs. 22 and 23. The first observation is that the pressure oscillations close to both the blade leading and trailing edges are of very low amplitudes, and practically independent of the frequency of blade oscillations (change in frequency is at a given port reflected as a change in acceleration). Second, the amplitude of pressure fluctuations over most of the leading half of the blade increases with an increasing frequency of blade oscillations. The phase of the pressure fluctuations seems not to be affected by frequency of blade oscillations, and depends only on the port position on the blade surface. The only exception is the case of Mach number 0.5 for location close to the trailing edge; the phase jumps over $90 d g$ for a blade frequency of $400 \mathrm{~Hz}$ as seen in Fig. 22. Reasons for this sudden change are not readily obvious.

\section{TWO-DIAPHRAGM PRESSURE SENSOR}

An alternative solution to eliminate acceleration effects on measured pressures is presented in Ref. 8. In this approach a flat surface-mounted pressure transducer consists of two diaphragms placed next to each other. One diaphragm is exposed to the ambient pressure, while the other is in a sealed enclosure. The first diaphragm senses pressure and acceleration changes, whereas the second one registers the acceleration effects only. A pressure signal free of acceleration effects can be retrieved by simply subtracting the signal of the sealed transducer from the signal of the exposed sensor. This custom made transducer was tested for steady centrifugal acceleration and worked very well. There is no report yet about the performance of this transducer under fluctuating acceleration loading. This innovative approach, however, also has several drawbacks. First, both diaphragms must have identical sensitivity of diaphragm deflections to acceleration. It is our experience that diaphragm sensitivity to deflections varies even for commercial transducers from the same batch. Second, the transducer will require two channels of data recording system to acquire one signal of unsteady pressure. Third, the transducer is bulkier than the existing single diaphragm transducers, and therefore the transducer cannot be placed close to the blade leading or trailing edges. Finally, the transducer is not commercially available and is expected to be more costly. 


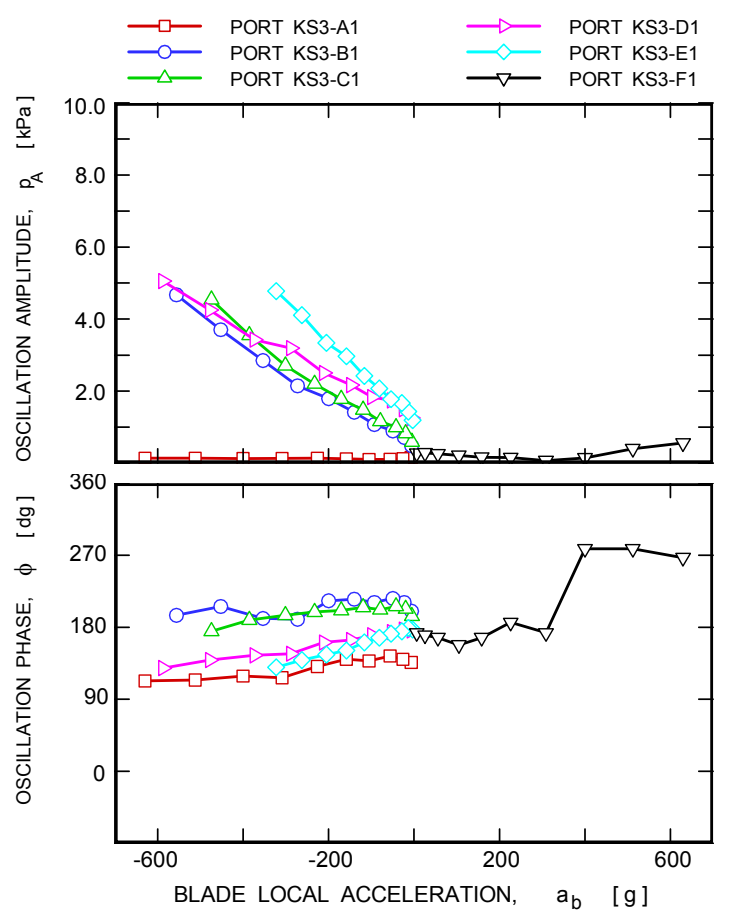

Fig. 22 Pressure signals from body-mounted transducers for inlet Mach number of 0.5 .

\section{FREQUENCY RESPONSE OF CONNECTING TUBES}

As stated above the flat surface-mounted pressure transducers could not be placed closer to the blade leading or trailing edges than $5 \%$ of the blade chord. A body-mounted pressure transducer equipped with a connecting tube can have the sensing port located up to the very edge of the blade. The penalty for this is a decreased natural frequency of the setup. A connecting tube essentially acts as a low-pass filter attenuating the high frequency content of the unsteady pressure signal. A connecting tube essentially acts as a low-pass filter attenuating the high frequency content of the unsteady pressure signal. A system consisting of a tube connected to a miniature pressure transducer has a natural frequency that was determined using the following formula based on speed of sound (a), tube length $(L)$, and tube diameter $(d)$. This formula has been verified by experiments described in Ref. 9:

$$
f_{N}=\frac{a}{4(L+0.3 d)}
$$

As a rule, the maximum frequency of interest should not exceed $80 \%$ of the natural frequency. The length of connecting tubes on blade $K S 3$ (with the exception of port $D$ ) is $14.0 \mathrm{~mm}$. Consequently, the pressure signal should be free of significant distortion up to a frequency of $4.6 \mathrm{kHz}$, which is sufficiently high even for the maximum frequency of blade oscillation of $500 \mathrm{~Hz}$. To verify this assumption, one of the transducer (port $D$ ) was inserted with a connecting tube with the minimum possible length of $2 \mathrm{~mm}$. Comparing data from transducers

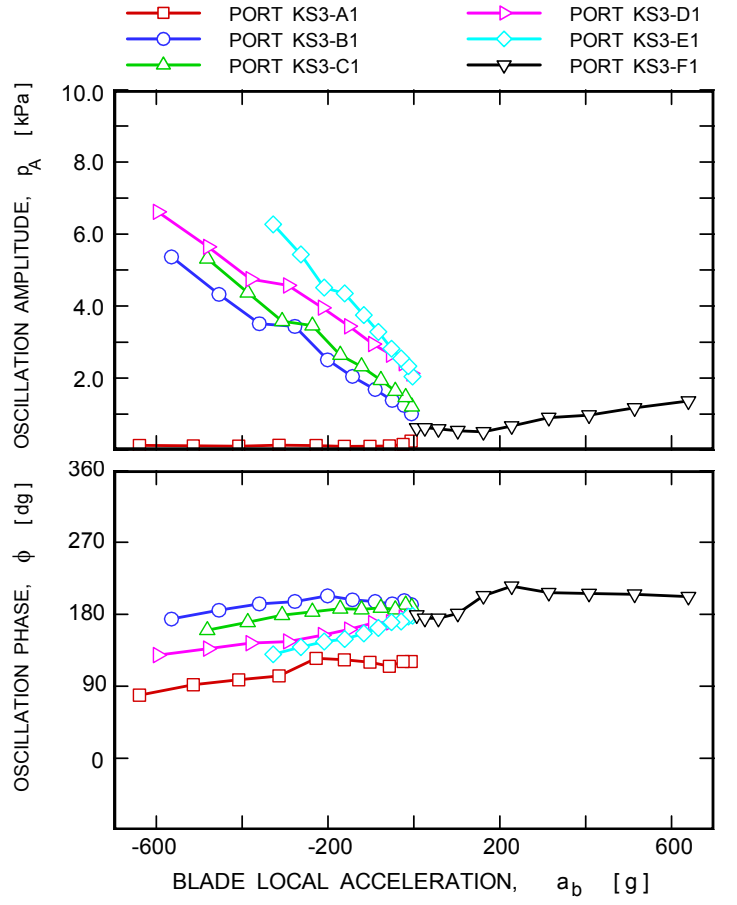

Fig. 23 Pressure signals from body-mounted transducers for inlet Mach number of 0.8 .

connected to ports $D$ and $E$, the effects of tube lengths can be evaluated. These transducers have connecting tubes of different length but they are reading unsteady pressures from practically same location on the blade (see Fig. 19).

The unsteady pressures measured by transducers $D$ and $E$ are shown in Fig. 24 for three blade oscillation frequencies of $100 \mathrm{~Hz}, 300 \mathrm{~Hz}$, and $500 \mathrm{~Hz}$, and a cascade inlet Mach number of 0.8 . As seen here, there is no visible difference between signals of these two transducers for a blade oscillation frequency of $100 \mathrm{~Hz}$. For the blade oscillations frequency of $300 \mathrm{~Hz}$ and higher, the signal for the transducer with a longer connecting tube is smoother and missing some of the high frequency oscillations; however, the essential character of the unsteady pressure signal is not altered. This qualitative observation is substantiated by Fig. 25 that presents frequency spectra for both transducers. As seen here, the longer tube filters out only high frequency noise (between $1.5 \mathrm{kHz}$ and $4.0 \mathrm{kHz}$ ) with amplitudes below $0.1 \mathrm{kPa}$ that do not significantly contribute to the overall signal frequency content. The basic harmonics of the signal, up to the seventh harmonic (for $f_{B}=500 \mathrm{~Hz}$ ) are not altered at all. The multiple lines at frequencies about $100 \mathrm{~Hz}$ are due to resonance effects in the cascade facility (Ref. 10), and are not caused by blade oscillations. Therefore, it can be concluded that data acquired by transducers with connecting tubes of length $14 \mathrm{~mm}$ in length is fully representative of the actual frequency content of the real pressure signal. 


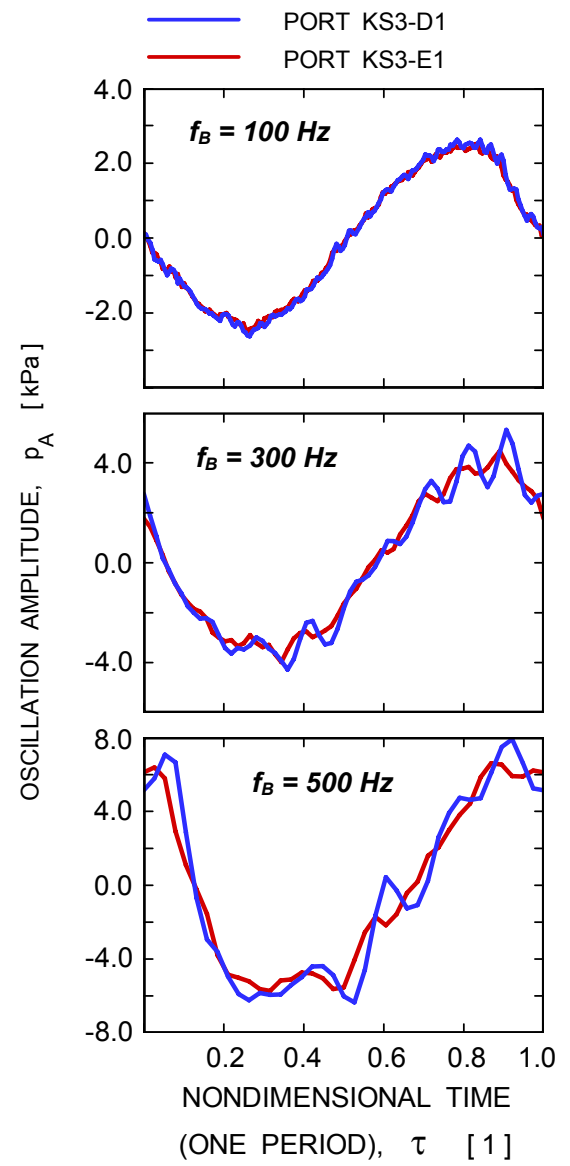

Fig. 24. Comparison of pressure signals from transducers with long and short connecting tubes for inlet Mach number of 0.8 .

\section{PRESSURE FLUCTUATIONS ON THE BLADE}

The analysis above reinforces the conviction that the true unsteady pressure signal along the oscillating blade can be reliably determined directly using body-mounted miniature pressure transducers or using surface-mounted transducers and applying corrections for acceleration effects. Data presented in Fig. 26 further support this statement. Beyond any doubt the amplitude of forced unsteady pressure fluctuations rapidly increases pat the oscillating blade leading edge, reaches its maximum at about the mid-point of the blade upstream half (left of the pitching axis), and then decays to a relatively low level just past the blade midchord. The fluctuation level stays low over the entire downstream half (right of the pitching axis) of the oscillating blade. Although these results can be obtained from transducers mounted in either way, the advantages of the body-mounted transducers are obvious. The body-mounted transducers do not require correction for accelerations effects, they are less expensive, their survival rate is much higher, and the surface of interest is not disturbed by transducer installation.

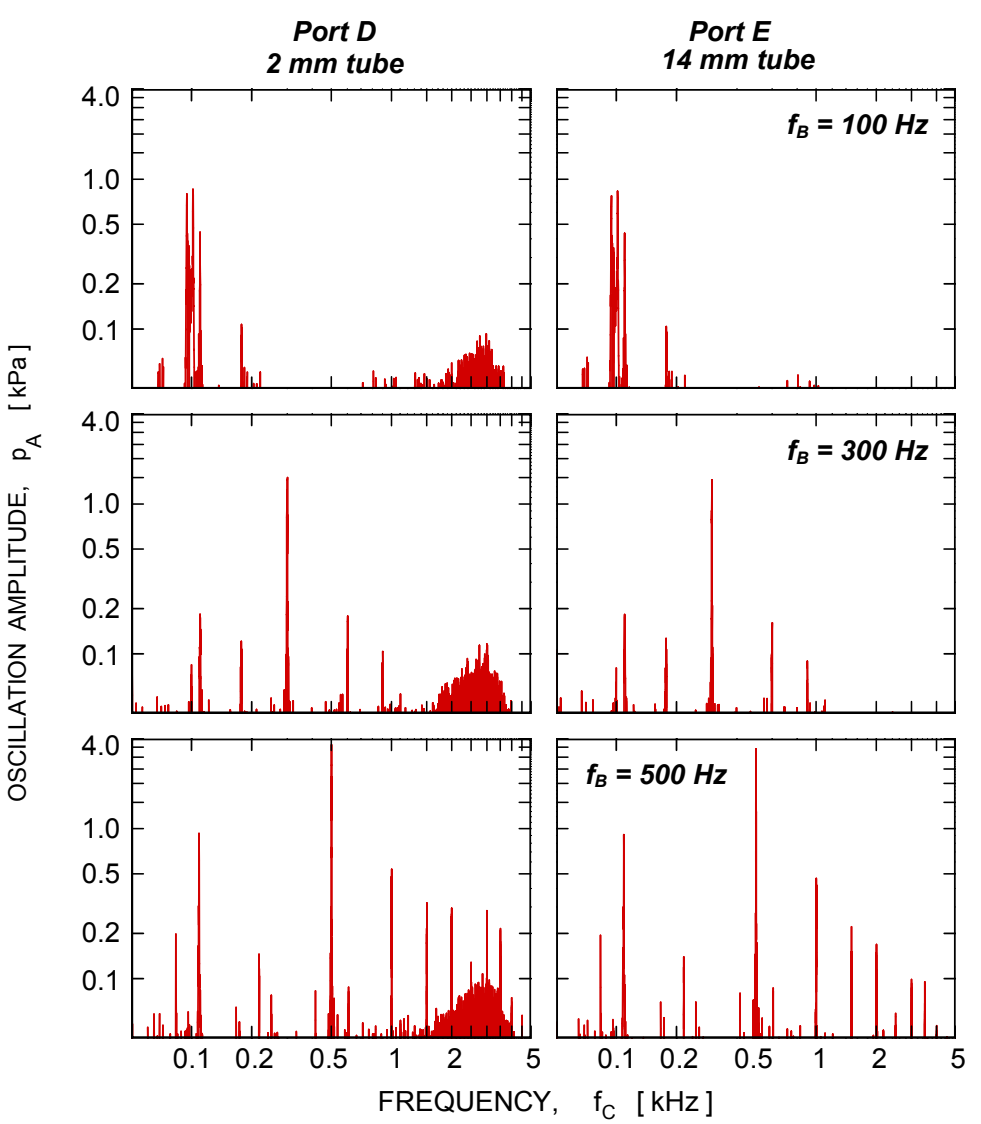

Fig. 25. Frequency spectra for unsteady pressure signals from transducers with short and long connecting tubes for cascade inlet Mach number of 0.8 .

\section{CONCLUSIONS}

Miniature pressure transducers were installed in an oscillating blade to measure unsteady pressures above the oscillating blade suction surface. The transducers were mounted in the blade in two ways: surface-mounted flat custom-made transducers, and conventional body-mounted transducers. The following conclusions were reached:

- transducers mounted in both ways can produce a true unsteady pressure signal provided the signal of the surface-mounted transducer is corrected for acceleration effects;

- body-mounted transducers are practically insensitive to acceleration effects, and their signal does not require any additional corrections;

- body-mounted transducers are much more resilient to mishandling damage, and their survival rate is much higher compared with surface-mounted transducers;

- conventional transducers utilized for body-mounted installation are substantially less expensive than the custom surface-mounted transducers; 


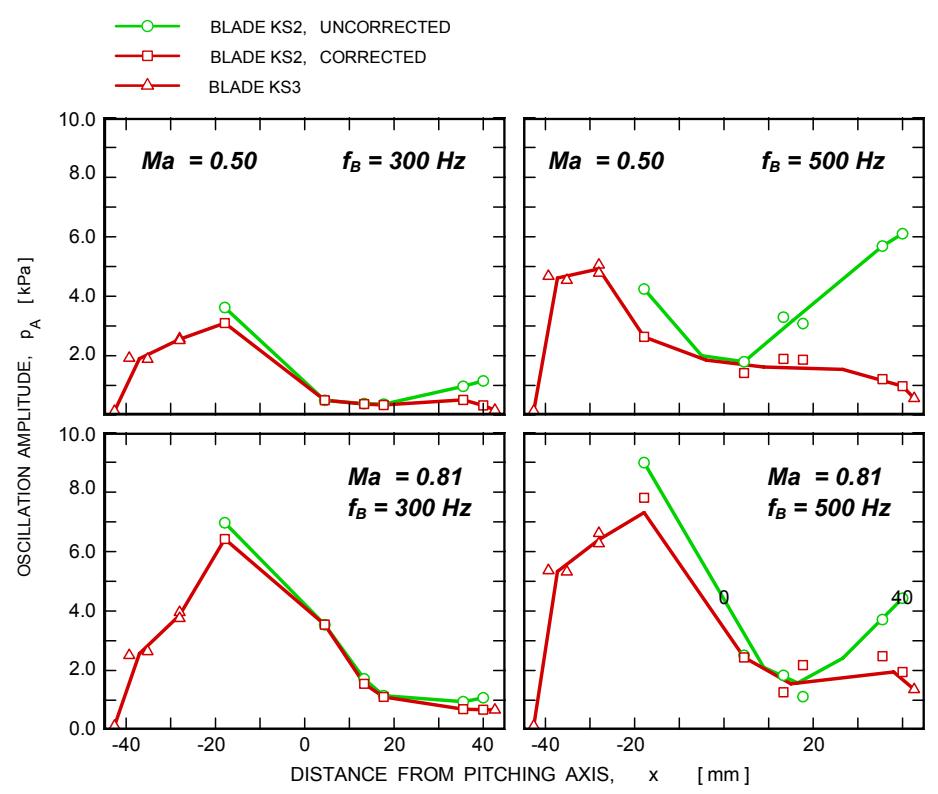

Fig. 26. Unsteady pressure distributions on the suction side of an oscillating blade.

- the length of the connecting tubes for body-mounted transducers must be adjusted to the maximum expected frequency of the unsteady pressure signal;

- in summary, the utilization of body-mounted conventional miniature pressure transducers is preferable to using the surface-mounted custom-made flat transducers.

\section{REFERENCES}

1. Boldman, D.R. and Buggele, A.E.: "Wind Tunnel Tests of a Blade Subjected to Midchord Torsional Oscillations at High Subsonic Stall Flutter Conditions", NASA TM-78998, 1978.
2. Shaw, L.M., Boldman, D.R., Buggele, A.E., and Buffum, D.H.: "Unsteady Pressure Measurements on a Biconvex Airfoil in a Transonic Oscillating Cascade", Journal of Engineering for Gas Turbines and Power, Vol. 108, pp. 53-59, 1986.

3. Buffum, D.H., Capece, V.R., King, A.J., and ElAini, Y.M.: "Experimental Investigation of Unsteady Flows at Large Incidence Angles in a Linear Oscillating Cascade", AIAA Paper 962823; also NASA TM-107283, 1996.

4. Lepicovsky, J., McFarland, E.R., Chima, R.V, and Wood, J.R.: "On Flowfield periodicity in the NASA Transonic Flutter Cascade," Journal of Turbomachinery, Vol. 123, pp. 501-509, 2001.

5. Lepicovsky, J., McFarland, E.R., Capece, V.R., Jett, T.A., and Senyitko, R.G.: "Methodology of Blade Unsteady Pressure Measurement in the NASA Transonic Flutter Cascade", NASA TM2002-211894, 2002.

6. Buffum, D.H., Capece, V.R., King, A.J., and El-Aini, Y.M.: "Oscillating Cascade Aerodynamics at Large Mean Incidence", NASA TM-107247, 1996.

7. Capece, V.R., Ford, C.T., and Bone, C.: 'Unsteady Aerodynamic Response of a Linear Cascade of Airfoils in Separated Flow", Status Report Grant NAG-2695, NASA GRC 2004.

8. Kurtz, A.D., Ainsworth, R.W., Thorpe, S.J., and Ned, A.: "Acceleration Insensitive Semiconductor Pressure Sensors for High Bandwidth Measurements on Rotating Turbine Blades", Paper at XVth biennal Symposium on Measurement techniques in Transonic and Supersonic Flows in Cascade and Turbomachines, Florence 2000.

9. Lepicovsky, J.: "Measurement of Unsteady Velocity Field at the Exit of a Radial Impeller", Dissertation Work (in Czech language), Czech Technical University, Prague 1977.

10. Lepicovsky, J., Capece, V.R., and Ford, C.T.: "Resonance Effects in the NASA Transonic Flutter Cascade Facility", NASA/CR-2003-212384, also ASME Paper GT-200338344, 2003. 


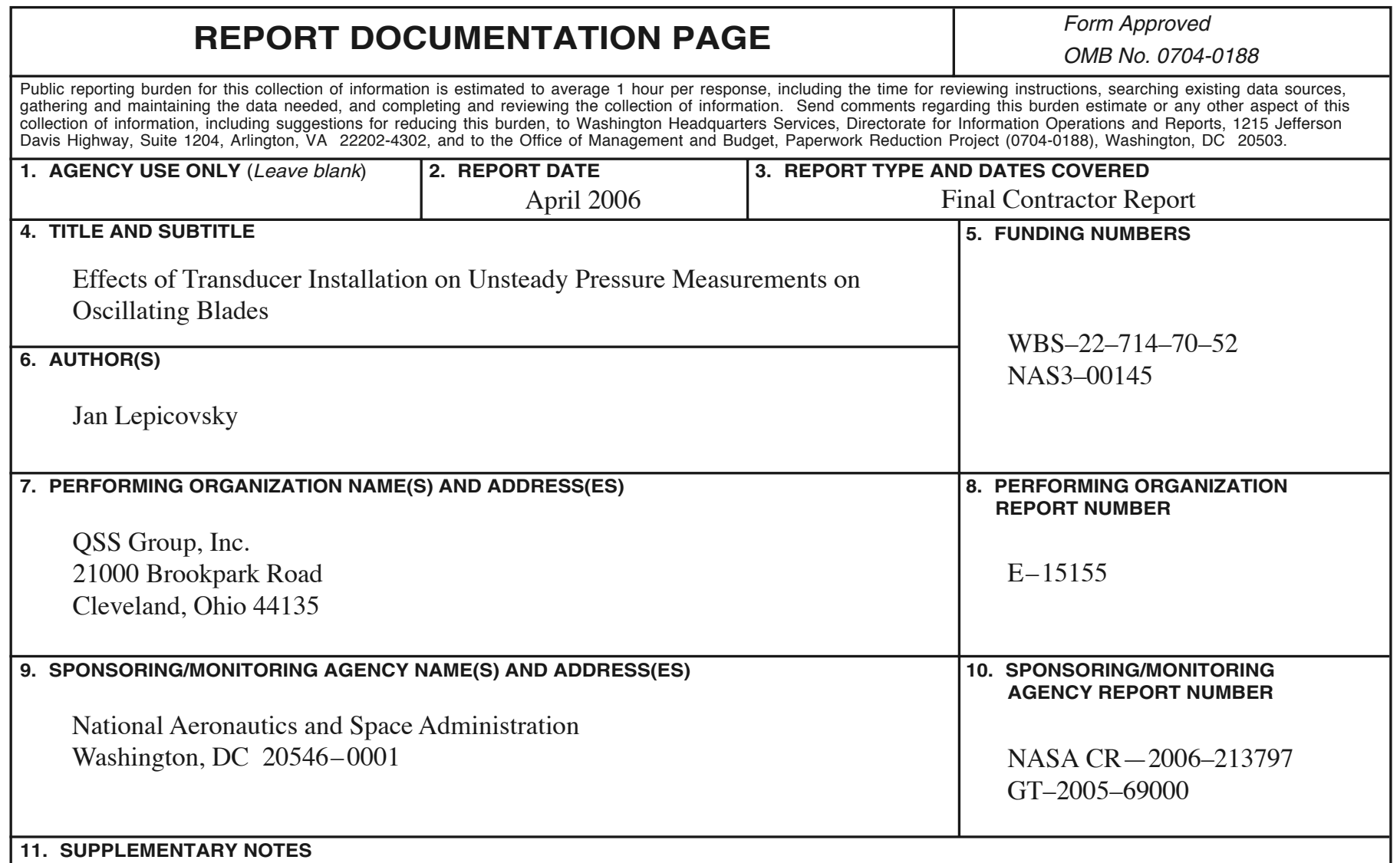

Prepared for Turbo Expo 2005 sponsored by the American Society of Mechanical Engineers, Reno, Nevada, June 6-9, 2005. Project Manager, Eric R. McFarland, Propulsion Systems Division, NASA Glenn Research Center, organization code RTC, 216-433-5915.

\begin{tabular}{|l|l|l|l|l}
\hline 12a. DISTRIBUTION/AVAILABILITY STATEMENT & DISTRIBUTION CODE
\end{tabular}

Unclassified - Unlimited

Subject Categories: 02, 07, and 35

Available electronically at http://gltrs.grc.nasa.gov

This publication is available from the NASA Center for AeroSpace Information, 301-621-0390.

13. ABSTRACT (Maximum 200 words)

Unsteady pressures were measured above the suction side of a blade that was oscillated to simulate blade stall flutter. Measurements were made at blade oscillation frequencies up to $500 \mathrm{~Hz}$. Two types of miniature pressure transducers were used: surface-mounted flat custom-made, and conventional miniature, body-mounted transducers. The signals of the surface-mounted transducers are significantly affected by blade acceleration, whereas the signals of body-mounted transducers are practically free of this distortion. A procedure was introduced to correct the signals of surface-mounted transducers to rectify the signal distortion due to blade acceleration. The signals from body-mounted transducers, and corrected signals from surface-mounted transducers represent true unsteady pressure signals on the surface of a blade subjected to forced oscillations. However, the use of body-mounted conventional transducers is preferred for the following reasons: no signal corrections are needed for blade acceleration, the conventional transducers are noticeably less expensive than custom-made flat transducers, the survival rate of body-mounted transducers is much higher, and finally installation of body-mounted transducers does not disturb the blade surface of interest.

\begin{tabular}{|c|c|c|}
\hline \multicolumn{3}{|c|}{$\begin{array}{l}\text { 14. SUBJECT TERMS } \\
\text { Instrumentation; Unsteady flow; Flutter }\end{array}$} \\
\hline $\begin{array}{l}\text { 17. SECURITY CLASSIFICATION } \\
\text { OF REPORT } \\
\text { Unclassified }\end{array}$ & $\begin{array}{l}\text { 18. SECURITY CLASSIFICATION } \\
\text { OF THIS PAGE } \\
\text { Unclassified }\end{array}$ & $\begin{array}{l}\text { 19. SECURITY CLASSIFICATION } \\
\text { OF ABSTRACT } \\
\text { Unclassified }\end{array}$ \\
\hline
\end{tabular}

NSN 7540-01-280-5500

Standard Form 298 (Rev. 2-89)

Prescribed by ANSI Std. Z39-18 298-102 

